\title{
Declarative Sentence Spectrograph Produced by Children with Autism
}

\author{
Ika Septiana ${ }^{1}$, Bambang Yulianto ${ }^{1}$, Kisyani Laksono ${ }^{1}$ \\ ${ }^{1}$ Universitas Negeri Surabaya, Jalan Ketintang Surabaya 60231 Indonesia \\ Email: ikawa27@yahoo.co.id
}

\begin{abstract}
The purpose of this paper is to describe the concept of Indonesian toward autistic children. Everyone can produce a language sound. It can also be done by autistic children. Autistic children a re special kids. Those children have special ability. Even though they are special, but their speaking ability has some language problems. Autists produce utterances with intonation up and down. Intonation of children with autism has its uniqueness. In terms of talking or communicating, children with autism have a distinctive tone of speech. Their speech tones can occur in the form of a spectrograph that is using Praat program. The technique that is used in collecting the data is observation and interview. Recording the speech of children with autism is being the main data. The data of this research is Indonesian declarative sentences produce by them. Sources of research data is the speech of children with autism. The object of research is a declarative sentence spectrograph. The data are analized using qualitative descriptive.
\end{abstract}

\section{Keywords: declarative sentence; spectrograph; autism; autistic children}

\section{INTRODUCTION}

The important thing that is the basis of a sentence is the basic constituent and final intonation. The halal conjunction only exists when necessary. Basic Constitution is usually a clause. The intonation clause will eventually form a sentence. Basic constituents can not be in clause, and word or phrase [1].

Surono states that declarative sentence is a sentence that gives information [2]. Sentences that do not have a formative marker, for example an interrogative sentene has question words while imperative sentences have command word such as, let's get it, etc. The down tone in suprasegmental can be the marker in declarative sentence while a written sentence will ended with period (.). The sample book is mine.

Verhaar analyzes the tone present within numbers 1 to 5 [3]. For number 1 the tone is low and increases as the number increases. In phonologically, there are two main segment elements. The first segment appears as an interlude, symbolized by a comma. The second segment is the rest. The first segment starts at a decreasing 
intonation, then rises steadily until interlude. The rise and fall intonation is phonemic because it symbolizes that there is a following segment.

After that interlude, the intonation continues to decline until the end of the sentence. The sound was phonemic as well, because it represented the end of a declarative sentence.

Zahid noted that the sophistication of computer technology can seek all the parameters visualized [3]. One of computer program is Praat program. Praat is the most sophisticated computer program created and used extensively today. This program specifically handles sound data. It is used in the field of linguistics to examine the sound of language in the form of spectrograph.

Lieshout Praat program tutorial provides An introduction to some basic procedures in Praat program [4]. This program can be downloaded for free. The Praat program can be used for the analysis and reconstruction of acoustic voice signals. The software can be downloaded from the site http://www.fon.hum.uva.nl/praat/ written by Sidney Wood. Praat can be used on different operating systems (see Praat website for more information), but this tutorial is based on Windows $2000 \mathrm{OS}$. It is a very flexible tool for conducting speech analysis. The program offers a wide range of nonstandard standards and procedures, including spectrographic analysis, articulation synthesis, and neural networks.

The spectrograph referred to in this article describes of the austistic children's declarative sentences. The program used to describe the authors' declarative sentence spectrograph using the Praat program. The Praat program is used to get the data and provides programs in sound waves and spectrograph analysis.

\section{METHODS}

The method used in data collection is by observation and interview techniques. Data collection techniques by recording children's speech autism. The data of this research is Indonesian declarative sentence. The sources of this research is speech of autistic children. Autistic children from SDLB Talitakum Semarang are the source of data. The object of research is a declarative sentence spectrograph. The data analysis used is qualitative descriptive.

\section{FINDINGS AND DISCUSSION}

The Praat program can produce a p icture of sound waves that describe the slimness, loudness, and length of a sound. It is depicted in spectrogram and form. Zahid's Praat program will produce the F0 parameter reading, which is an abbreviated form referring to the fundamental frequency perceived by the listener as the slimness, intensity, the volume of voice and duration, known as an extension [3].

The Praat program is used to get the declarative sentence spectrograph. The declarative sentence described in this article is part of the Ika Septiana research result entitled Pola Intonasi Kalimat Bahasa Indonesia Anak Autis. Declarative sentences used by autistic children will be described in this article though lima, Bu Ika, gonta 
ganti matras, and cek. Declarative sentences are spoken autistic children. This tutorial is a natural remark from an autistic child. The data obtained is the natural speech of autistic children in the form of chatter or answers to questions. The speech of autistic children is obtained through questions and answers and lure of speech. Autistic children can not produce a lot of words, although only a single word, it is still shows a sentence. The word production is followed by final intonation. Here is a picture of a declarative authorship sentence spectrogram from autistic children.

\section{(1) Lima}

Data (1) is a speech from autistic child with using a final intonation decreasing. The strain there is pressure when the autistic child spoke the word lima. The pressure is on the syllable li and ma. The intonation that follows when the speech word is a decreasing intonation that is the meaningful point of ending the word. Therefore the word is a declarative sentence.

Children with autism spoke the data (1) followed by intonation at the end of the word is decreased. It means to inform others. The word lima spoken by autistic children mean numbers. Data (1) is the autism children's answer to the question of the researcher who answered five meaning the child home at five o'clock. Data (1) means a time.

Speech can be seen using the Praat program in the form of sound waves. Here is a picture of lima declarative sentence spectrographs in an autistic child's speech.

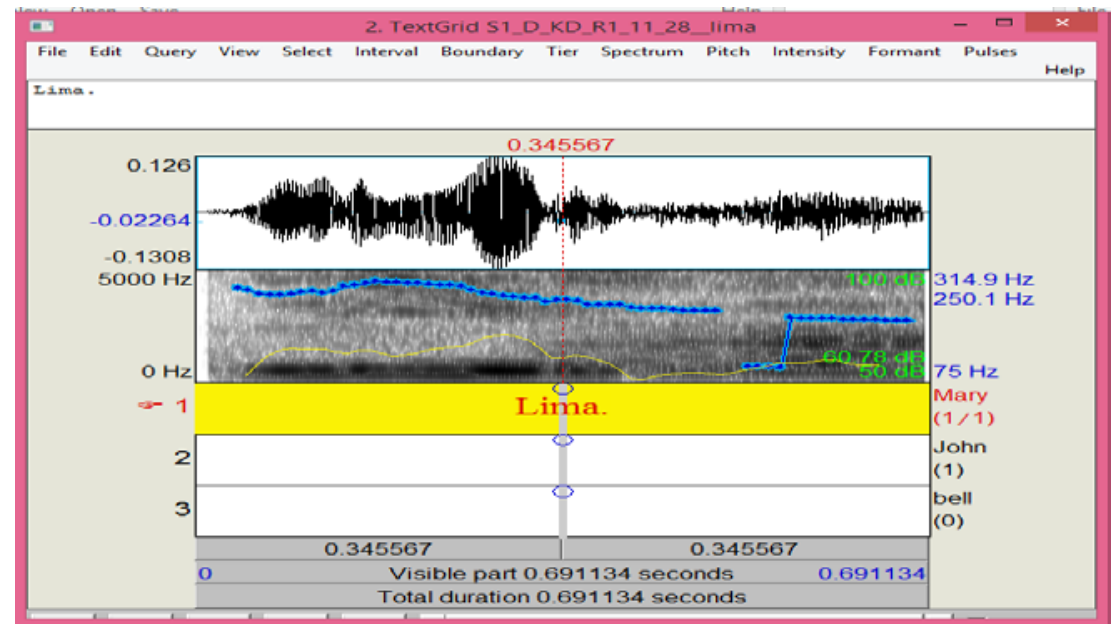

Figure 1. Spectogram Lima

The data spectrograph (1) illustrates the amount of energy employed to say the word lima. It also illustrates the format that is exposed with a point-splicing point straight or transverse. Below the "dotted-line" there is a swirling line, it refers to the 
slimness of the active up and down represents the intensity and loudness of the voice when speaking the word Lima.

The image spectrograph (1) consists of three parts: the first part is a spectrograph where the picture that appears black and white lines tightly apart. Data (1) is spoken with a total duration of 0.691134 second. The second part there is made up two parts namely pitch and intensity. Show pitch denotes a blue line indicating frequency. This section describes the data (1) is spoken with a frequency of 250.1 $\mathrm{Hz}$. It shows intensity of volume through the yellow line. The intensity data (1) is $60.78 \mathrm{~dB}$. The third part of text grid shows the declarative sentence on the spectrograph. That part is written as the declarative sentence that is Lima.

\section{(2) $\mathrm{Bu} I \mathrm{ka}$}

Data (2) is speech words from autistic children by using final intonation decreases. The tug is a pressure when the autistic childr speech the data (2). The pressure is in the syllable $\underline{b u}$ and $i k a$ the intonation that follows when the word is spoken is a decreasing intonation which is the meaningful point of ending the word. Therefore the word is a declarative sentence.

Autistic child pronoun the data (2) followed by intonation at the end of the word that is decreased. It means to inform others. $\mathrm{Bu} I \mathrm{ka}$ is spoken by an autistic children meaningful greeting someone or a person's name. Data (2) is the autistic child's answer to the researcher's question. The autism children's answer is in the data (2) which illustrates that the child is still familiar with the name of the person who is communicating even though he has met only a few times. The speech can be seen by using Praat program in the form of sound waves. Here is a picture of declarative sentence expression Bu Ika produced by autistic child.

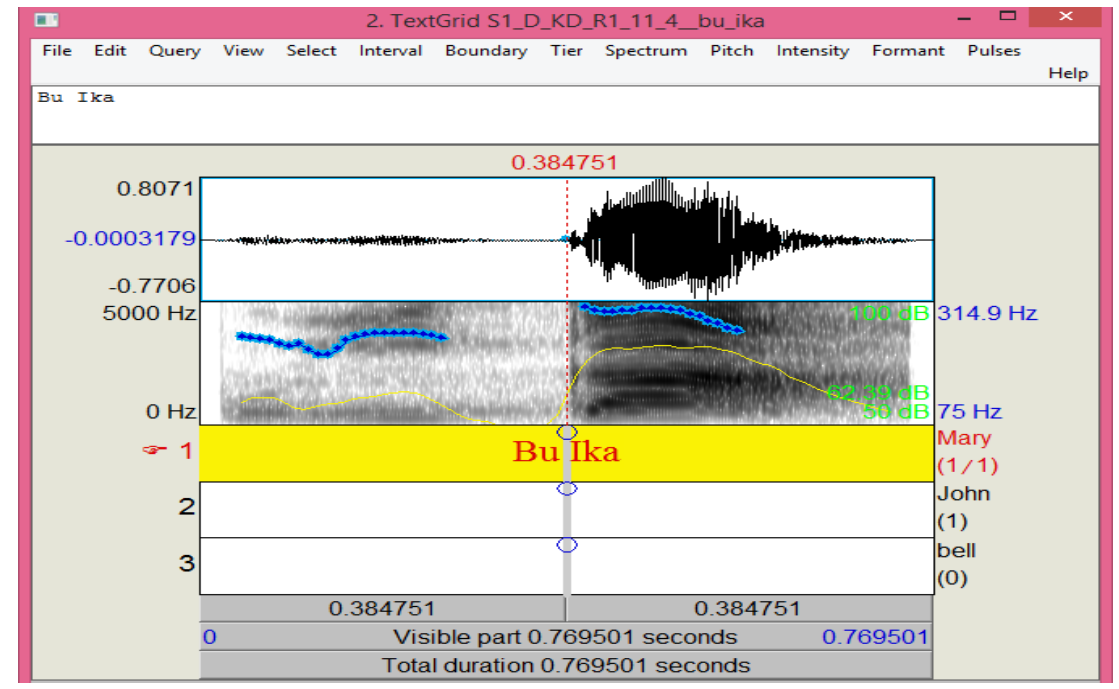

Figure 2. Spectogram Bu Ika 
The data spectrograph (2) illustrates the amount of power used to speak the word $\mathrm{Bu} I \mathrm{ka}$. It also illustrates the format that is exposed with a point-splicing point straight or transverse. Below the "dotted-line" there is a swirling line, it refers to the slimness of the active up and down which represents the intensity and loudness of the voice when speaking the word Bu Ika.

Spectrogram picture (2) above includes three parts, namely the first part of the spectrograph is a picture with black and white lines tightly apart. Data (2) is spoken with a total duration of $0.769501 \mathrm{~s}$ econds. The second part there are two parts namely pitch and intensity. The pitch denotes a blue line indicating frequency. This section describes the data (2) is spoken with a frequency of $314.9 \mathrm{~Hz}$. The intensity of volume through the yellow line. The data intensity (2) is illustrated $62.39 \mathrm{~dB}$. The third part of text grid shows the declarative sentence on the spectrograph. The section is written declarative sentence that is $\mathrm{Bu} I \mathrm{ka}$.

\section{(3) Gonta-ganti Matras}

Data (3) by the autistic speech is unique. The utterance is an autism children chatter. The child expresses declarative sentence spontaneously according to the one in his heart and mind. In addition to this uniqueness there is a sound spoken on the word "mat". Part of the sound changes when the autistic child spoke matras. The lines that appear are not matras but matlas. The sound [r] turns into [1].

[matras] - [matlas]

$[\mathrm{r}] \quad-\quad[1]$

Sound changes occur for several reasons. The child finds it difficulty to pronounce $[\mathrm{r}$ ] on the word matras The sound [r] has phonetic similarity with [1] because sounds [r] and [1] are in the same lane of the alveolar sound. Sound [1] is pairs of sounds [r] that has phonetic similarities. The sound [r] is adjacent to sound [1] because the sound [1] is lateral and [r] is a tril. Hence the spoken and audible utterance of the autistic children's speech on the word matras becomes matlas.

In the data (3), the autism children pronounce the word gonta-ganti. Word gonta-ganti is the morphological result of repeating of the basic form of the dressing. After repeated changes sounds mutually. There is a change of sound [a] to [o] so that it becomes gonta-ganti.

Data (3) is spoken by autistic child by using final intonation that decreases. The tug is a pressure when the autism children uttered the data (2). The pressure is in the syllable gon ta-gan ti mat las. The intonation that follows when the word spoken is a decreasing intonation which is the meaningful point of ending the word. Therefore the word is a declarative sentence.

The autistic child spoke data (3) followed by the intonation at the end of the word that is decreased. It means to inform others. The word gonta ganti matras is produced by an autistic child az a meaningful greeting or a person's name. Data (3) is the autistic children's answer to the researcher's question and the autism children's answer is data (3) which means that the child still recognizes the name of the person he or she is communicating with. 
The speech can be seen by using the Praat program in the form of sound waves. Here's a picture of a declarative sentence spectrograph gonta ganti matras produced by autistic child.

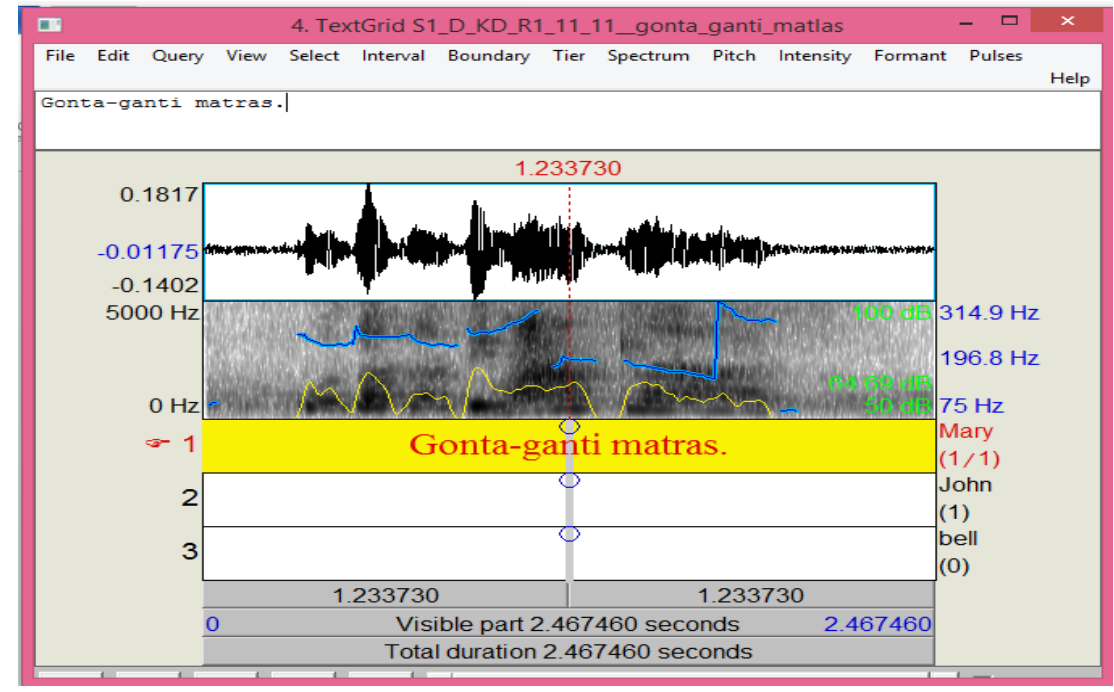

Figure 3. Spectogram Gonta ganti matras

The data spectrograph (3) illustrates the amount of energy used to describe the mutual declarative sentence for gonta ganti matras. It also illustrates the format that exposed with a point-splicing point straight or transverse. Below the "dotted-line" there is a swirling line, which refers to the slimness of the active ups and downs representing the intensity that refers and the loudness of the voice when it says the declarative sentence for gonta ganti matras.

The data spectrograph (3) consists of three parts, namely the first part of the spectrograph is the image with black and white lines tightly apart. Data (3) is spoken with a total duration of 2.467460 seconds. The second part is made up of namely pitch and intensity. The pitch denotes a blue line indicating frequency. This section describes the data (3) is spoken with a frequency of $196.8 \mathrm{~Hz}$. The volume intensity through the yellow line. Intensity data (3) illustrated $64.69 \mathrm{~dB}$. The third part of text grid shows the declarative sentence on the spectrograph. The section is written declarative sentence that is gonta ganti matras

(4) Cek.

Data (4) spoke by autistic children using final intonation decreases. It is stressed when the autistic child utters the data (4). The pressure is on the syllable cek. The intonation that follows when the word spoken is a decreasing intonation which is a meaningful point of ending the word. Therefore the word is a declarative sentence. 
An autistic child inform other using intonation at the end of the word that is decreased. Sentence cek is spoken by an autistic child with autism meaningful information. The purpose of data tutoring (4) is the autism children tells others to radio to check first. The speech can be seen by using the Praat program in the form of sound waves. Here is a p icture spectrograph of declarative sentence cek for produced by autistic child.

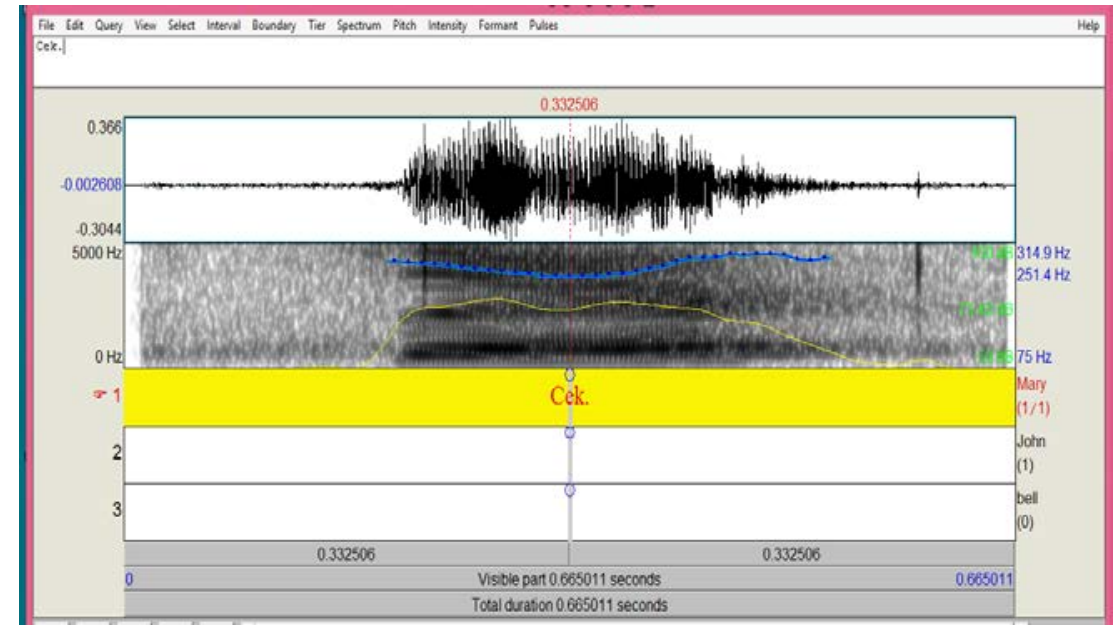

Figure 4. Spektogram Cek.

The data spectrograph (4) illustrates the amount of power used to express the declarative sentence cek. It also illustrates the format that is exposed with a pointsplicing point straight or transverse. Below the dotted line there is a swirling line, it refers to the slimness of active up and down represents the intensity and loudness of the voice when it says declarative sentence cek.

The data spectrograph (4) consists of three parts, namely the first part of the spectrograph is the image with black and white lines tightly apart. Data (3) is spoken with a total duration of 0.665011 seconds. The second part is made up two parts pitch and intensity. The pitch is denote by a blue line indicating frequency. This section describes the data (3) is spoken with a frequency of $251.4 \mathrm{~Hz}$. Show intensity of describing the yellow line that shows the volume. Intensity data (3) illustrated 73.42 $\mathrm{dB}$. The third part of text grid shows the declarative sentence on the spectrograph. The section is written declarative sentence is a cek.

Based on the data spectrograph diagram (1) through (4) the sound measured from sound waves indicate the volume rises at the beginning of the sound and decreases at the end of the sound. It shows that the declarative sentence in the autistic child ends as the sound waves decreasing. Based on the spectrum of declarative sentences the autistic child's speech ends with a decreasing sound. Intonation contained in the authors declarative sentence autism ends with intonation 1. 
The spectrogram is sound waves of the autistic child shows pitch at low and high intensity of low and high limits. The pitch depicted by the a blue line indicate the frequency of a declarative sentence represented by the same frequency is low frequency $75 \mathrm{~Hz}$ and high frequency $314.9 \mathrm{~Hz}$. The volume intensity describes a yellow line indicates the loudness of a declarative sentence illustrated a low intensity of $50 \mathrm{~dB}$ and a high intensity of $100 \mathrm{~dB}$.

Chaer (1978: 60-61) the loudness of a spech sound relative to the loudness of the preceding or the following sounds is called it is intensity. The purpose of seeing whether or not intensity is a defining feature of Indonesian word accent. Intensity is measure in decibels $(\mathrm{dB})$. The intensity of the sound A is said to be higter than the intnsity of the sound B if and when the difference in decibels between $A$ and a given point of reference is greater than that between $B$ and the point of reference.

\section{CONCLUSION}

Declarative sentences produced by autistic children include lima, Bu Ika, gonta ganti matras, and cek is spontaneously spoken. This tutorial is the natural speech of autistic children in the form of babble or answers to questions. There is also speech that is less in line with the question. Declarative sentence speech of children with autism is in the form of words. Despite the word, it is a sentence.

Spectrogram declarative sentence speech of autism children is measured by sound waves, that indicate the rise in volume at the beginning of the sound and the drop at the end of the sound. Spectrogram show rising sound waves and a decrease at the end of the sound. It shows that the declarative sentence in the autistic child ends with the sound waves decreasing. Based on the declarative sentence spectrogram an autistic child's speech ends with a decreasing sound, then the intonation contained in the authors declarative sentence autism ends with 1 intonation.

\section{REFERENCES}

[1] Chaer, Abdul. 2007. Linguistik Umum. Jakarta: Rieneka Cipta, pp. 241.

[2] Surono. 2014. Analisis Frasa-Kalimat Bahasa Indonesia. Semarang: Gigih Pustaka Mandiri, pp. 135.

[3] Verhar, J.W.M. 2006. Asas-Asas Linguistik Umum. Yogyakarta: Gajah Mada University Press, pp. 87-90.

[4] Zahid, Indrawati and Mardian Shah Omar. 2012. Fonetik dan Fonologi. Selangor: Bandar Damansara Perdana, pp. 6-7.

[5] Lieshout, Pascal van. 2013. "Praat Short Tutorial V. 4.2.1", presented at PRAAT Workshop Manual v241, October 7, 2003

[6] Halim, Amran. 1974. Intonation in Relation to Syntax in Bahasa Indonesia. Depdikbud:Jambatan. Pp 62-63. 